Volume 3, Issue 1, pages 93-100

p-ISSN 2655-8564, e-ISSN 2685-9432

\title{
Effects of Shock Wave Phenomenon on Different Convergent Lengths in the Mixing Chamber of the Steam Ejector
}

\author{
Stefan Mardikus ${ }^{1, *}$ \\ ${ }^{1}$ Department of Mechanical Engineering, Faculty of Science \\ and Technology, Sanata Dharma University, Yogyakarta, Indonesia \\ *Corresponding Author: stefan@usd.ac.id
}

(Received 26-03-2021; Revised 24-04-2021; Accepted 05-05-2021)

\begin{abstract}
The shock wave phenomenon is a phenomenon in a steam ejector that caused when the working fluid has high pressure, and suddenly it turns into low pressure and high speed. The shock wave effect will be investigated to the different convergent length in the mixing chamber to find the highest entrainment ratio as the performance of steam ejector. Operating pressure in the primary flow was in the range $0.68 \mathrm{MPa}-1.39 \mathrm{MPa}$, and the secondary flow was set $0.38 \mathrm{MPa}$ to $0.65 \mathrm{MPa}$. The result of this study demonstrated that the highest entrainment ratio occurred in the convergent length of 69 $\mathrm{mm}$.
\end{abstract}

Keywords: Steam ejector, shock wave, convergent length

\section{Introduction}

The Steam Ejector is a utilization that is used to recover waste energy from low pressure fluid (secondary pressure) and low thermal energy to high-pressure fluid (primary pressure) without the use of the moving part and electrical energy 


\section{International Journal of Applied Sciences and Smart Technologies}

Volume 3, Issue 1, pages 93-100

p-ISSN 2655-8564, e-ISSN 2685-9432

resources [1]. On the other hand, the steam ejector can be used to mixing fluid in the chemical industry when the fluid has different physical properties through operating condition by pressure or temperatures of fluid. The steam ejector system was applied in many industries as power plant, refrigeration, food processing technology, etc. For example, the difficult problem to handle the liquid or gas corrosively in process industries, the ejector can pump this fluid through different pressure when the primary fluid passed part of the nozzle; thus; the secondary fluid can be moved to the mixing chamber area [2]. The primary fluid that has high pressure and temperature when passed the nozzle decreased the pressure and temperature. Moreover, the fluid flow of the primary fluid shaped expansion angle in the mixing chamber; therefore, the lowpressure fluid as secondary fluid can entrain the ejector's system. In the chemical industry, the steam ejector was used to mix the substance with different properties of physics. Furthermore, the steam ejector model geometry consists of the nozzle and mixing chamber area like convergent, throat and divergent is an essential part to enormously improve the steam ejector performance [3].

In many investigations of steam ejector performance, Navid and Majid optimized the nozzle to reduce the steam ejector system's energy across the nozzle geometries. The investigation proved that the nozzle geometries' improvement could augment the entrainment ratio of steam ejector [4]. Meanwhile, the shockwave phenomenon in the convergent and divergent nozzle was evaluated by Yinhai that the increase of shockwave length can decrease characteristic of the steam ejector performance [5]. The shockwave phenomenon appears when the working fluid has high pressure, and suddenly it turns into low pressure and high speed. Furthermore, the expansion angle of fluid flow will show. One of the strategies to improve the steam ejector's performance will be investigated based on the shockwave phenomenon in the mixing chamber area. This paper will be experimentally evaluated by the different convergent length that can provide shock wave phenomenon with several operating pressure conditions in primary and secondary flow to find the highest entrainment ratio at the different of convergent length. 


\section{International Journal of Applied Sciences and Smart Technologies}

Volume 3, Issue 1, pages 93-100

p-ISSN 2655-8564, e-ISSN 2685-9432

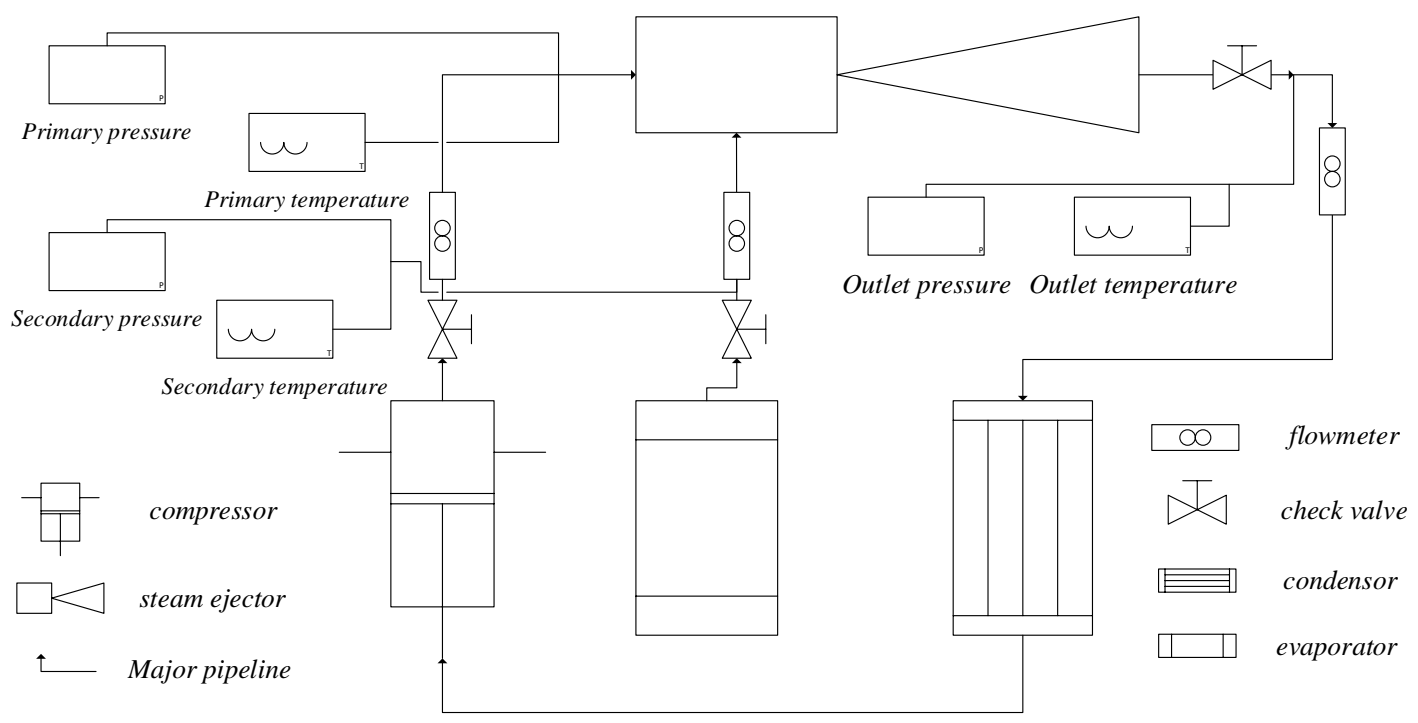

Figure 1. The schematic of steam ejector experimental.

\section{Research Methodology}

The schematic of the experimental steam ejector can be seen in Figure 1. The part of the main experimental setup consists of a steam ejector (1), compressor (2), condenser (3), an evaporator (4). In this research, $1 \mathrm{PK}$ compressor used to compress the primary fluid. The characteristic of the primary fluid, secondary fluid, and discharge fluid was measured by thermocouple type K and pressure gauge. Primary pressure and secondary pressure can be set using regulator valve. The primary pressure set to operate $0.68 \mathrm{MPa}$ to $1.39 \mathrm{MPa}$ and the secondary pressure $0.38 \mathrm{MPa}$ to $0.65 \mathrm{MPa}$. This study uses an R-22 as the working fluid. The condenser was an air cooled plate heat exchanger constructed from a 3/8inch diameter cooper pipe. The steam ejector geometry model can be seen in Figure 2, where the convergent length will be investigated with the different model. Three types of models of convergent length are $51 \mathrm{~mm}, 69 \mathrm{~mm}$, and $75 \mathrm{~mm}$. 


\section{International Journal of Applied Sciences and Smart Technologies}

Volume 3, Issue 1, pages 93-100

p-ISSN 2655-8564, e-ISSN 2685-9432

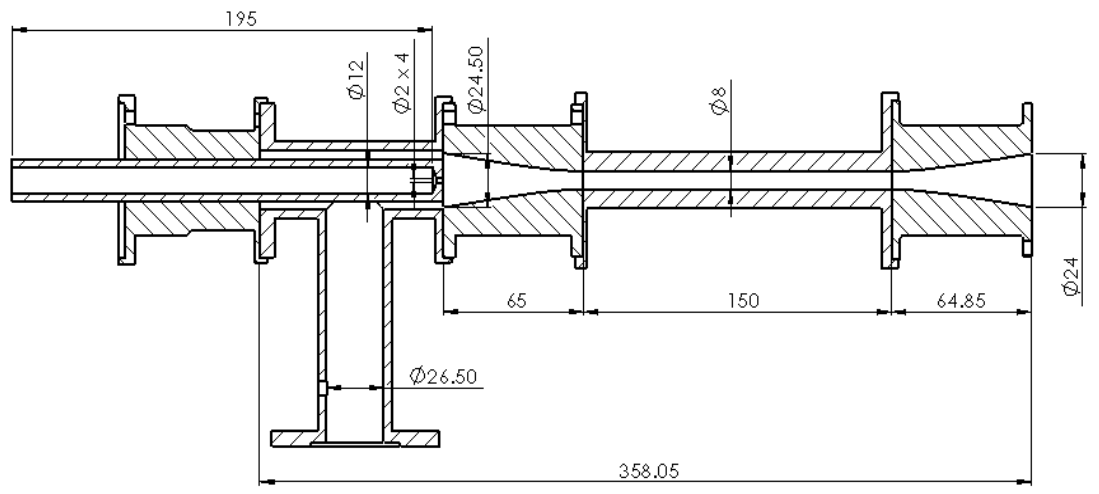

Figure 2. Geometry model of the steam ejector component.

\section{Results and Discussion}

As shown in Figures 3-6, our experiment results showed that the optimum entrainment ratio with different convergent length was on the convergent length $69 \mathrm{~mm}$ for all secondary pressure due to the shock wave phenomenon that appeared when the working fluid through the nozzle part decreased pressure and increasing velocity suddenly occurred. Increasing the primary pressure can augment the mass flow rate of working fluid into the mixing chamber.

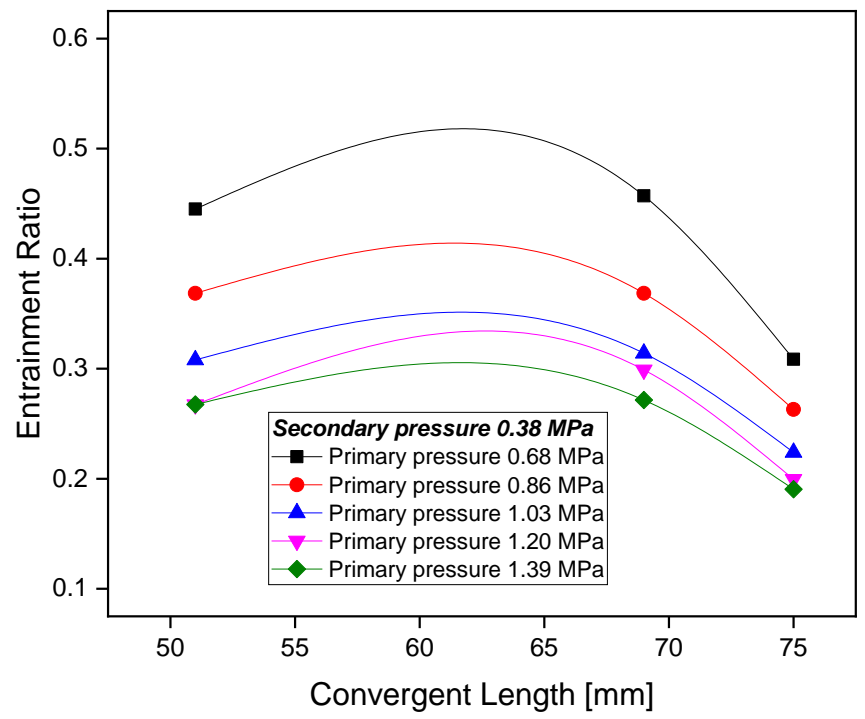

Figure 3. Effect of entrainment ratio versus the convergent length variations on secondary pressure $0.38 \mathrm{MPa}$ in case operations of primary pressure 


\section{International Journal of Applied Sciences and Smart Technologies}

Volume 3, Issue 1, pages 93-100

p-ISSN 2655-8564, e-ISSN 2685-9432

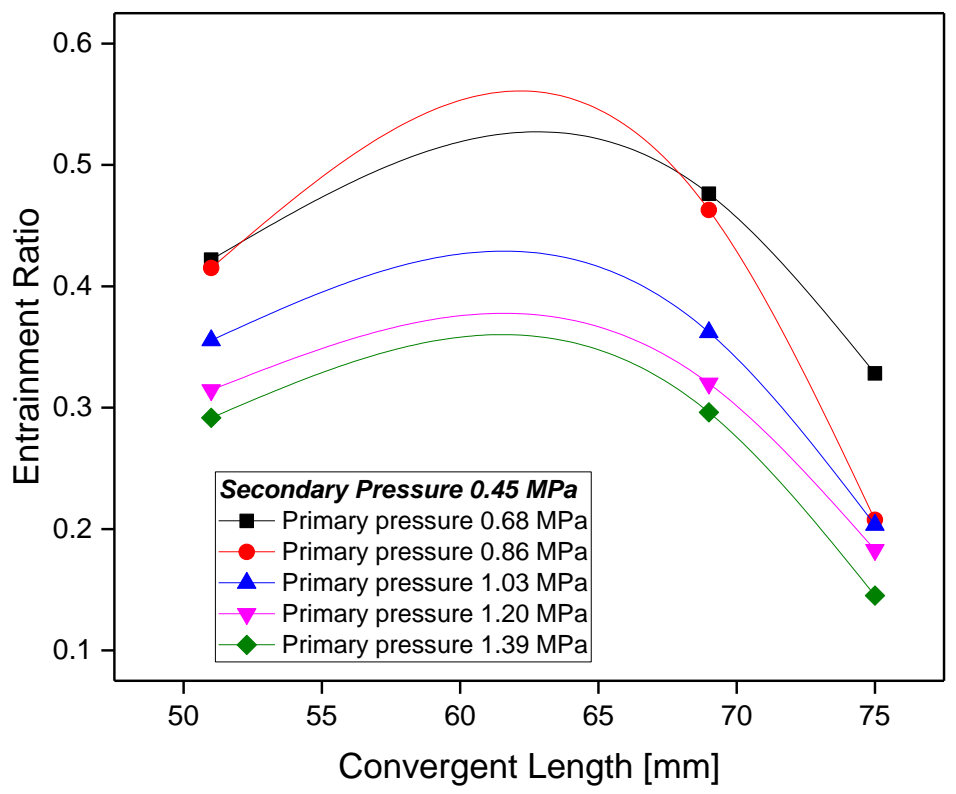

Figure 4. Effect of entrainment ratio versus the convergent length variations on secondary pressure $0.45 \mathrm{MPa}$ in case operations of primary pressure

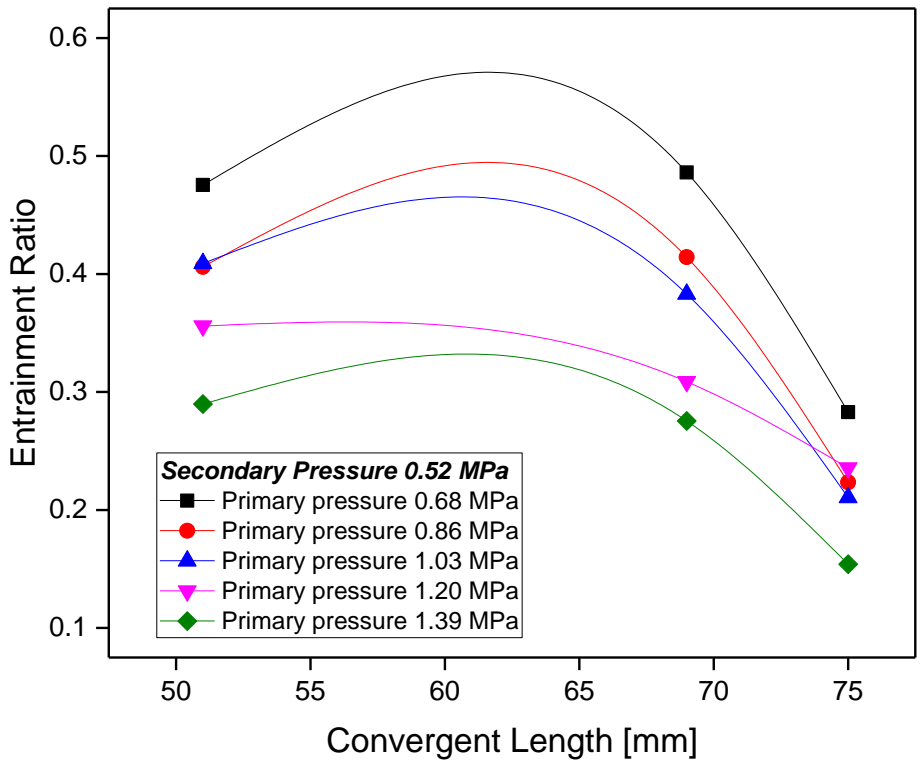

Figure 5. Effect of entrainment ratio versus the convergent length variations on secondary pressure $0.52 \mathrm{MPa}$ in case operations of primary pressure 


\section{International Journal of Applied Sciences and Smart Technologies}

Volume 3, Issue 1, pages 93-100

p-ISSN 2655-8564, e-ISSN 2685-9432

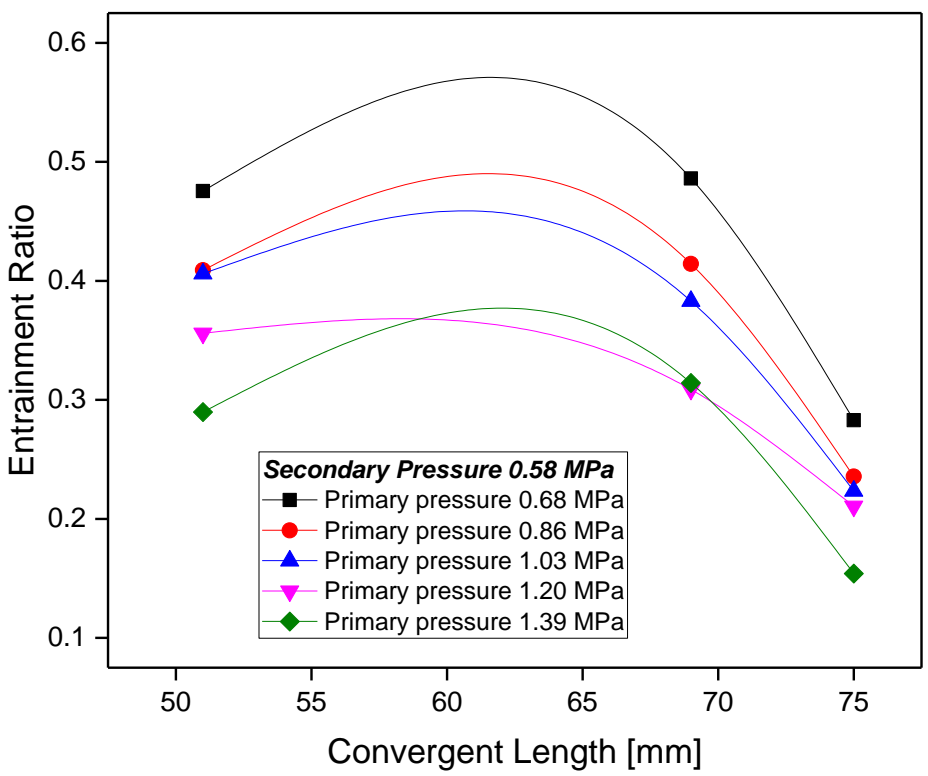

Figure 6. Effect of entrainment ratio versus the convergent length variations on secondary pressure $0.58 \mathrm{MPa}$ in case operations of primary pressure

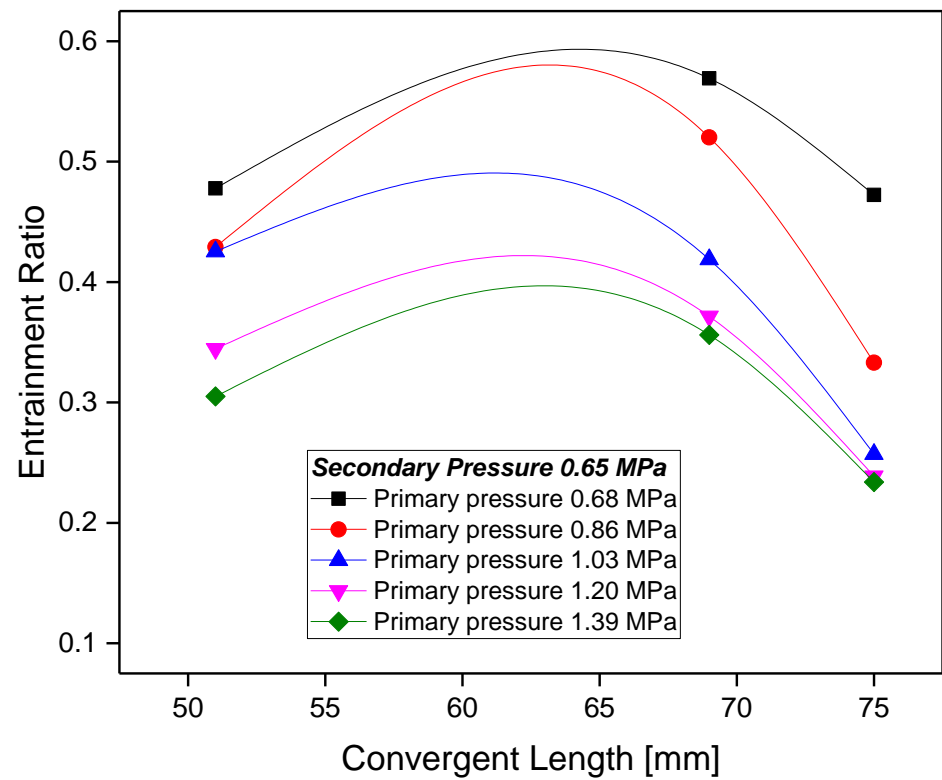

Figure 7. Effect of entrainment ratio versus the convergent length variations on secondary pressure $0.65 \mathrm{MPa}$ in case operations of primary pressure 


\section{International Journal of Applied Sciences and Smart Technologies}

Volume 3, Issue 1, pages 93-100

p-ISSN 2655-8564, e-ISSN 2685-9432

In Figure 7, the highest entrainment ratio occurred at the primary pressure of 0.68 $\mathrm{MPa}$. This experiment was found that operating of primary pressure could effect the entrainment ratio as the performance of steam ejector. At the same of the primary pressure, when the convergent length more extensive, the entrainment ratio slightly decreased at all of operating pressure in secondary because there was a small expansion angle in convergent length that more extensive [6]. When it happened, the mass flow rate of secondary pressure slightly reduced to move into the steam ejector's mixing chamber [5]. This phenomenon was caused by entraining duct shorter in the suction chamber area [2].

\section{Conclusion}

Based on experimentally evaluated results, the different convergent length in the mixing chamber could influence the steam ejector performance like an entrainment ratio. The shock wave phenomenon occurred when working fluid passed the nozzle area, and it could provide the diamond shock wave in the mixing chamber. The diamond shock wave phenomenon became one of the important things that caused the entrainment of steam ejector was augmented; thus; on this investigation, the highest entrainment ratio was occurred in the convergent length of $69 \mathrm{~mm}$.

\section{References}

[1] J. Dong, X. Chen, W. Wang, C. Kang, and H. Ma, “An experimental investigation of steam ejector refrigeration system powered by extra low temperature heat source.” Int. Commun. Heat Mass Transf., 2017.

[2] V. V. Chandra and M. R. Ahmed, "Experimental and computational studies on a steam jet refrigeration system with constant area and variable area ejectors.” Energy Convers. Manag., 2014.

[3] N. Ruangtrakoon, S. Aphornratana, and T. Sriveerakul, "Experimental studies of a steam jet refrigeration cycle: Effect of the primary nozzle geometries to system performance.” Exp. Therm. Fluid Sci., 2011.

[4] N. Sharifi and M. Sharifi, "Reducing energy consumption of a steam ejector through experimental optimization of the nozzle geometry." Energy, 2014. 
International Journal of Applied Sciences and Smart Technologies

Volume 3, Issue 1, pages 93-100

p-ISSN 2655-8564, e-ISSN 2685-9432

[5] Y. Zhu and P. Jiang, "Experimental and analytical studies on the shock wave length in convergent and convergent-divergent nozzle ejectors." Energy Convers. Manag., 2014.

[6] Y. Wu, H. Zhao, C. Zhang, L. Wang, and J. Han, "Optimization analysis of structure parameters of steam ejector based on CFD and orthogonal test.” Energy, 2018. 